\title{
Histoire sommaire de la maladie et du somnambulisme de Lady Lincoln, présenté par Nicole Edelman, Luis Montiel, Jean-Pierre Peter
}

\section{Michel Arrrous}

\section{CpenEdition}

1 Journals

\section{Édition électronique}

URL : http://journals.openedition.org/studifrancesi/5990

DOI : ERREUR PDO dans /localdata/www-bin/Core/Core/Db/Db.class.php L.34 : SQLSTATE[HYO00

[2006] MySQL server has gone away

ISSN : 2421-5856

\section{Éditeur}

Rosenberg \& Sellier

\section{Édition imprimée}

Date de publication : 1 mai 2011

Pagination : 181

ISSN : 0039-2944

\section{Référence électronique}

Michel Arrrous, "Histoire sommaire de la maladie et du somnambulisme de Lady Lincoln, présenté par Nicole Edelman, Luis Montiel, Jean-Pierre Peter », Studi Francesi [En ligne], 163 (LV | I) | 2011, mis en ligne le 30 novembre 2015, consulté le 08 janvier 2021. URL : http://journals.openedition.org/ studifrancesi/5990 ; DOI : https://doi.org/10.4000/studifrancesi.5990

Ce document a été généré automatiquement le 8 janvier 2021. 


\title{
Histoire sommaire de la maladie et du somnambulisme de Lady Lincoln, présenté par Nicole Edelman, Luis Montiel, Jean-Pierre Peter
}

\author{
Michel Arrrous
}

\section{RÉFÉRENCE}

Aa. Vv., Histoire sommaire de la maladie et du somnambulisme de Lady Lincoln, présenté par Nicole Edelman, Luis Montiel, Jean-Pierre Peter, Paris, Tallandier, 2009, pp. 285.

1 Les stendhaliens et les balzaciens connaissent David-Ferdinand Koreff (Breslau, 1783-1851, Paris), médecin magnétiseur qui introduisit Hoffmann en France. Fixé à Paris en 1823, il fut pour Stendhal le «sublime», le «charmant» Koreff, «le plus moqueur des hommes», un «Allemand homme d'esprit», mais aussi, et c'est Balzac qui le dit en 1846, un «infâme espion». Ajoutons qu'il se rendit auprès de Léonor Mérimée et qu'il apparaît furtivement dans Arsène Guillot. Avec la publication de ce manuscrit qui, contrairement à ce qui est affirmé dans la préface, n'est pas de la main de Koreff - il s'agit d'une copie faite par un scribe professionnel - et qui d'ailleurs n'est pas une révélation (BNF, Ms, n.a.f. 1408), le lecteur pourra juger sur pièces de la méthode de Koreff, associé à son confrère Wolowski, pour tenter de comprendre et de guérir une patiente exceptionnelle, Lady Suzan Lincoln, fille du duc de Hamilton et belle-fille du duc de Newcastle, qui séjourna à Paris en 1837, où elle arriva quasiment à l'agonie. Les deux médecins mirent en œuvre une thérapie hétérodoxe, inspirée de la Naturphilosophie et du magnétisme animal. La cure, de près quatre mois, se solda par un échec et un procès retentissant intenté par les familles aux deux médecins. À la suite de quoi, et après une intervention de la Faculté que Stendhal déplora, la carrière de Koreff déclina sensiblement, jusqu'à ce qu'une nouvelle affaire, avec les héritiers de la 
«dame aux camélias», la brise définitivement. On dispose donc d'un utile complément à la notice fort riche du Petit Dictionnaire stendhalien et à celle du Dictionnaire de Stendhal, ainsi qu'au livre ancien de Marietta Martin (1925, Slatkine Reprints, 1977). Auraient pu être mentionnés la notice de Martineau, le livre du Dr Cabanès, Un Médecin prussien, espion dans les salons romantiques (1916), ainsi que le travail de Deborah Hertz, Jewish High Society in Old Regime Berlin (1988, rééd. 2005); cependant la postface de Luis MONTIEL fournit des informations sur la carrière allemande de Koreff. L'ouvrage est illustré du beau portrait de Koreff par le peintre de cour Hensel et de celui du marquis de Douglas et de Lady Suzan Hamilton par Lawrence. 